\title{
Pierre Schoentjes, Silhouettes de l'ironie, «Romanica Gandensia» XXXIV
}

Gabriella Bosco

\section{(2) OpenEdition}

\section{Journals}

\section{Edizione digitale}

URL: http://journals.openedition.org/studifrancesi/8432

DOI: $10.4000 /$ studifrancesi.8432

ISSN: 2421-5856

\section{Editore}

Rosenberg \& Sellier

\section{Edizione cartacea}

Data di pubblicazione: 1 mai 2009

Paginazione: 227-228

ISSN: 0039-2944

\section{Notizia bibliografica digitale}

Gabriella Bosco, «Pierre Schoentjes, Silhouettes de l'ironie, «Romanica Gandensia» XXXIV», Studi

Francesi [Online], 157 (LIII | I) | 2009, online dal 30 novembre 2015, consultato il 11 janvier 2021. URL: http://journals.openedition.org/studifrancesi/8432 ; DOI: https://doi.org/10.4000/studifrancesi.8432

Questo documento è stato generato automaticamente il 11 janvier 2021.

\section{(c) (i) (9)}

Studi Francesi è distribuita con Licenza Creative Commons Attribuzione - Non commerciale - Non opere derivate 4.0 Internazionale. 


\title{
Pierre Schoentjes, Silhouettes de l'ironie, «Romanica Gandensia» XXXIV
}

\author{
Gabriella Bosco
}

\section{NOTIZIA}

PIERRE SCHOENTJES, Silhouettes de l'ironie, «Romanica Gandensia» XXXIV, Genève, Droz, 2007, pp. 372.

1 Ritrarre l'ironia è arduo quanto «peindre un lutin avec le bonnet qui le rend invisible»: nella sua introduzione, Pierre SCHOENTJES usa questa similitudine prendendola a prestito da Søren Kierkegaard per illustrare, del suo oggetto di studio, la natura insieme oscura ed evidente.

2 In un saggio del 2001, Poétique de l'ironie (Seuil), l'A. aveva affrontato l'argomento da un punto di vista eminentemente teorico, l'ironia in quanto procedimento retorico, giungendo a fornirne una formulazione descrittiva come di «un mode indirect et dissimulateur qui joue sur l'écart entre des sens en opposition». Già era implicita in quella formula la necessità dell'interpretazione, e dunque l'implicazione del lettore, nel meccanismo del'ironia. E Schoentjes, già all'epoca, sottolineava un'altra proprietà fondamentale dell'ironia, la sua natura valutativa. Tre ragioni insomma d'interesse per tornare a occuparsene: il suo triplice afferire alla retorica, all'ermeneutica e all'etica.

3 Ma questa volta l'A. intende far parlare i testi, e il volume raccoglie letture protratte per una quindicina d'anni, spesso già pubblicate singolarmente in rivista o oggetto di comunicazione in svariati convegni.

4 Quattro le sezioni che strutturano l'insieme. Il primo gruppo di articoli («Perspectives $\left.\mathrm{XIX}^{\mathrm{e}}{ } », \mathrm{pp} .11-95\right)$ analizza l'ironia in testi del XIX secolo. L'Ottocento, che ha visto la riattualizzazione del concetto da parte dei romantici tedeschi, è importante per la Francia - scrive Schoentjes - perché con Musset, Gautier, Flaubert, Sten-dhal o 
Mérimée ha preso corpo una letteratura ironica che vale tuttora come esemplare. In questa sezione, l'A. si occupa di autori che non sono normalmente studiati dal punto di vista dell'ironia, come Balzac e Huysmans, Jules Janin e Jules Verne.

5 La seconda sezione ( $«$ Figures du $\mathrm{xx}^{\mathrm{e}} »$, pp. 97-205) si occupa di testi che si scaglionano lungo tutto il Novecento arrivando fino al 2006. È un secolo molto ricco dal punto di vista della produzione ironica, secolo in cui inoltre il concetto d'ironia subisce una mutazione diventando per certi autori un quasi-sinonimo di letterarietà. Non è incluso Proust perché già trattato in quest'ottica da Schoentjes in un saggio specifico (Recherche de l'ironie et ironie de la "Recherche", Gand P.U.G., 1993). Gli autori studiati vanno da Gide a Camus, da Cohen a Vercors e Echenoz. Schoentjes non trascura opportunamente la francofonia e saggia l'opera dell'ivoriano Kourouma e del belga Toussaint.

Con la terza parte («Accents historiques», pp. 207-290), l'analisi proposta segue l'evoluzione delle idee sull'ironia tra il 1880 e la fine della Prima Guerra mondiale, offrendo la possibilità di cogliere il valore morale che certi autori attribuiscono al suo uso.

7 L'ultima sezione («Contours», pp. 291-370), raccoglie articoli che vanno oltre il contesto strettamente letterario. Vi è studiata la fotografia come agente dell'apparizione ironica delle cose e l'ironia nella società dei consumi. Per finire, Schoentjes riflette sull'ulteriore mutazione che il procedimento retorico dell'ironia sta subendo oggi, nel XXI secolo della postmodernità, ovvero sulla sua trasformazione nel metadiscorso per eccellenza. 